\title{
Metabolic, Ventilatory, and Hygric Physiology of the Gracile Mouse Opossum (Gracilinanus agilis)
}

\author{
C. E. Cooper ${ }^{1,2, *}$ \\ P. C. Withers ${ }^{1,2}$ \\ A. P. Cruz-Neto ${ }^{1,2,3}$ \\ ${ }^{1}$ Centre of Ecosystem Diversity and Dynamics, Department \\ of Environmental Biology, Curtin University of Technology, \\ P.O. Box U1987, Bentley Delivery Centre, Western Australia \\ 6845, Australia; ${ }^{2}$ Department of Zoology, School of Animal \\ Biology, Internal Mail M092, University of Western Australia, \\ Crawley, Western Australia 6009, Australia; ${ }^{3}$ Departmento de \\ Zoologia, Universidade Estadual Paulista, Avenida 24-A, Bela \\ Vista, Rio Claro, 13506-960 São Paulo, Brazil
}

Accepted 6/13/2008; Electronically Published 1/20/2009

\section{ABSTRACT}

We present the first complete study of basic laboratorymeasured physiological variables (metabolism, thermoregulation, evaporative water loss, and ventilation) for a South American marsupial, the gracile mouse opossum (Gracilinanus agilis). Body temperature $\left(T_{\mathrm{b}}\right)$ was thermolabile below thermoneutrality $\left(T_{\mathrm{b}}=33.5^{\circ} \mathrm{C}\right)$, but a substantial gradient between $T_{\mathrm{b}}$ and ambient temperature $\left(T_{\mathrm{a}}\right)$ was sustained even at $T_{\mathrm{a}}=$ $12^{\circ} \mathrm{C}\left(T_{\mathrm{b}}=30.6^{\circ} \mathrm{C}\right)$. Basal metabolic rate of $1.00 \mathrm{~mL} \mathrm{O}_{2} \mathrm{~g}^{-1}$ $\mathrm{h}^{-1}$ at $T_{\mathrm{a}}=30^{\circ} \mathrm{C}$ conformed to the general allometric relationship for marsupials, as did wet thermal conductance (5.7 $\left.\mathrm{mL} \mathrm{O}_{2} \mathrm{~g}^{-1} \mathrm{~h}^{-1}{ }^{\circ} \mathrm{C}^{-1}\right)$. Respiratory rate, tidal volume, and minute volume at thermoneutrality matched metabolic demand such that $\mathrm{O}_{2}$ extraction was $12.4 \%$, and ventilation increased in proportion to metabolic rate at low $T_{\mathrm{a}}$. Ventilatory accommodation of increased metabolic rate at low $T_{\mathrm{a}}$ was by an increase in respiratory rate rather than by tidal volume or $\mathrm{O}_{2}$ extraction. Evaporative water loss at the lower limit of thermoneutrality conformed to that of other marsupials. Relative water economy was negative at thermoneutrality but positive below $T_{\mathrm{a}}=$ $12^{\circ} \mathrm{C}$. Interestingly, the Neotropical gracile mouse opossums have a more positive water economy at low $T_{\mathrm{a}}$ than an Australian arid-zone marsupial, perhaps reflecting seasonal variation in water availability for the mouse opossum. Torpor occurred at low $T_{a}$, with spontaneous arousal when $T_{b}>20^{\circ} \mathrm{C}$. Torpor resulted in absolute energy and water savings but lower relative water economy. We found no evidence that gracile

\footnotetext{
*Corresponding author; e-mail: c.cooper@curtin.edu.au.
}

mouse opossums differ physiologically from other marsupials, despite their Neotropical distribution, sympatry with placental mammals, and long period of separation from Australian marsupials.

\section{Introduction}

Australia is widely perceived to be the major center of marsupial diversity (147 recent species in 55 genera of 16 families; Strahan 2002), and the majority of marsupial research involves Australian species. However, the marsupial fauna of South and Central America is also diverse, in terms of both species numbers (76 species representing 19 genera and four families) and occupied ecological niches (Emmons and Feer 1997; Eisenberg and Redford 1999). This American fauna represents a relict of a once more extensive marsupial radiation, and the four extant families that make up the Didelphimorphia are relatively distantly related, having been separate since the early Tertiary period (Tyndale-Biscoe 2005). The Didelphimorphia occupy a wide range of climates and habitats and include species with niches that have not been exploited by the Australian marsupial radiation (e.g., semiaquatic marsupials), but they are morphologically less diverse and show less dietary variation than Australian marsupials. This often-overlooked American fauna merits attention similar to that given to Australian marsupials, and it provides an important phylogenetic comparison with Australian species.

Our basic knowledge of the metabolic physiology of South American marsupials is limited to measurement of oxygen consumption $\left(\dot{\mathrm{V}}_{2}\right)$ and body temperature $\left(T_{\mathrm{b}}\right)$ for 13 species (Morrison and McNab 1962; McNab 1978; Dawson and Olson 1988; Nespolo et al. 2002; Bozinovic et al. 2004, 2005, 2007; Ribeiro and Bicudo 2007). This data set includes a single individual of a species of mouse opossum thought to be Marmosa microtarsus (now Gracilinanus microtarsus Tate 1932; Morrison and McNab 1962; Gardner and Creighton 1989). We are not aware of any study of ventilatory or hygric physiology for a South American marsupial.

Here we examine a further species of South American marsupial, the gracile mouse opossum (Gracilinanus agilis; family Didelphidae), to present the first complete data set for thermal, metabolic, ventilatory, and hygric physiology for a didelphid marsupial. We compare its physiology with that of other marsupials to examine potential environmental and adaptive responses in a Neotropical habitat. Gracile mouse opossums are small (adult mass 12-45 g), sexually dimorphic, short-lived (1$1.5 \mathrm{yr}$ ), partially semelparous, solitary, nocturnal, and predom- 
inantly arboreal marsupials that inhabit the Cerrado biome in southeastern and southern Brazil (Eisenberg and Redford 1999; Costa et al. 2003; Martins et al. 2006a, 2006b; Rossi et al. 2006). Extensive studies of this species indicated a predominantly insectivorous diet, with some fruit. (Martins and Bonato 2004; Martins et al. 2006c, 2006d).

\section{Material and Methods}

Nine adult nonreproductive gracile mouse opossums (seven males and two females) were trapped at the Clube Náutico Araraquara $\left(21^{\circ} 43^{\prime} \mathrm{S}, 48^{\circ} 01^{\prime} \mathrm{W}\right)$. The area is cerradão, a physiognomy of the cerrado biome characterized by a dense forest with tall trees and closed canopy, with marked seasonal variation in temperature and rainfall (see Martins et al. 2006a for a complete description of the study area). We consider that the species of mouse opossum studied here is Gracilinanus agilis based on the description, distribution, and habitat of this species (Tate 1933; Gardner and Creighton 1989; Costa et al. 2003; L. Costa, Universidade Federal do Espirito Santo, personal communication).

Gracile mouse opossums were captured in Sherman cage traps placed on tree branches $150-180 \mathrm{~cm}$ above ground level and baited with peanut butter and rolled oats, cat biscuits, and cod liver oil. Mouse opossums were returned to Universidade Estadual Paulista (UNESP), Rio Claro, and housed in individual wooden cages in an animal room maintained at approximately $23^{\circ} \mathrm{C}$ with a $12 \mathrm{~L}: 12 \mathrm{D}$ cycle. Opossums were provided with ad lib. food (tinned cat food, dry cat biscuits, mango, pawpaw, and banana) and water. Experiments commenced within 2 wk of capture, over the period of December-February 2006/2007.

Standard flow-through respirometry was used to measure rates of $\dot{\mathrm{V}}_{2}$, carbon dioxide production $\left(\dot{\mathrm{V}}_{\mathrm{CO}_{2}}\right)$, and evaporative water loss (EWL) at ambient temperatures $\left(T_{\mathrm{a}}\right.$ 's) of $12^{\circ}$, $20^{\circ}, 28^{\circ}, 30^{\circ}$, and $32^{\circ} \mathrm{C}$. We used three separate metabolic systems. Two systems consisted of an Aalborg mass flow controller (GFC17) that regulated compressed air at flow rates of 500 to 1,000 $\mathrm{mL} \min ^{-1}$ (depending on $T_{\mathrm{a}}$ ). Air then passed through a $360-\mathrm{mL}$ metabolic chamber that was in an Electrolab 122FC temperature control cabinet before passing through a Vaisala HMP 45A temperature and humidity probe. Calculated 99\% equilibrium times were 1.7-3.3 min (calculated after Lasiewski et al. 1966). A manifold was placed after the humidity probe, and $100 \mathrm{~mL} \mathrm{~min}{ }^{-1}$ of excurrent air was subsampled to measure $\mathrm{CO}_{2}$ and $\mathrm{O}_{2}$ levels (after air was dried with Drierite), using a Sable Systems Foxbox. The Vaisala temperature and humidity outputs were connected to the analog inputs of the Foxbox. The third system consisted of a Sable Systems two-channel mass flow controller (V 1.1), relative humidity (RH) meter (100 RH/ Dewpoint meter), TC-1000 thermometer, CA-2A CO $\mathrm{CO}_{2}$ analyzer, FC-1B $\mathrm{O}_{2}$ analyzer, and PP-2 dual subsampling pump (V 1.0). Flowmeters were calibrated using a bubble flowmeter, $\mathrm{O}_{2}$ analyzers were calibrated to room air $\left(20.95 \% \mathrm{O}_{2}\right)$, and $\mathrm{CO}_{2}$ analyzers were calibrated using a Cameron Instruments mass-flow gas mixer (model GF3/MP) at concentrations of $0.5 \%, 1.0 \%$, and $1.5 \% \mathrm{CO}_{2}$ in a $\mathrm{N}_{2} / \mathrm{O}_{2}$ mix. The calibration of the $\mathrm{RH}$ probes was confirmed using two points, $1 \% \mathrm{RH}$ (dried with Drierite to $0.005 \mathrm{mg} \mathrm{L} \mathrm{L}^{-1}$; http://www.drierite.com/default.cfm?goto _page $=$ page $4 \mathrm{a} . \mathrm{cfm}$ ) and $100 \% \mathrm{RH}$ (saturated; generated by breathing on the probe).

The two Foxboxes were each connected via an RS232 interface to a laptop PC, and the voltage outputs for $\mathrm{O}_{2}, \mathrm{CO}_{2}, \mathrm{RH}$, and $T_{\mathrm{a}}$ were recorded every $10 \mathrm{~s}$ with a custom-written Visual Basic (ver. 6) data acquisition program (P. Withers). The analyzers for the third system were interfaced to a PC using a Sable Systems UI2 analog-to-digital converter, and the output was recorded every $10 \mathrm{~s}$ with the same data acquisition program.

Ventilatory data were measured using the metabolic chamber as a whole-body plethysmograph (Malan 1973; Withers 1977; Dawson et al. 2000; Larcombe 2002; Cooper and Withers $2004 b$ ). Pressure changes due to the warming and humidifying of inspired air were detected with a custom-made pressure transducer (Motorola MPX2010 sensor; Physiology Department, University of Western Australia; systems 1 and 2) or a Sable Systems PT-100B pressure transducer (system 3). Analog voltage outputs from the pressure transducers were converted to digital signals using a Pico Technology ADC 11 data logger and were recorded on a PC every $15 \mathrm{~ms}$ for approximately 30 s using PicoScope. Between two and six sets of ventilatory data were obtained for an individual opossum at each $T_{\mathrm{a}}$, so a single mean was calculated for each ventilatory variable for each opossum at each $T_{\mathrm{a}}$. The plethysmography system was calibrated after Szewczak and Powell (2003).

Gracile mouse opossums were fasted for $24 \mathrm{~h}$ before the commencement of experiments. They were measured in the metabolic systems for no less than $8 \mathrm{~h}$ at each $T_{\mathrm{a}}$, during their inactive phase (day), until $\dot{\mathrm{V}}_{2}, \dot{\mathrm{V}}_{\mathrm{CO}_{2}}$, and EWL had become stable and minimal. We calculated $\dot{\mathrm{V}}_{2}, \dot{\mathrm{V}}_{\mathrm{CO}_{2}}$, and EWL at each $T_{\mathrm{a}}$ from the average of each variable over the 20-min period where they were stable and minimal. Calculations were after Withers (2000) and were accomplished using a custom written Visual Basic data analysis program (P. Withers). Respiratory exchange ratio (RER) and evaporative quotient (EQ) were calculated as $\dot{\mathrm{V}}_{\mathrm{CO}_{2}} / \dot{\mathrm{V}}_{2}$ and EWL $/ \dot{\mathrm{V}}_{2}$, respectively. Wet $\left(C_{\text {wet }}\right)$ and dry $\left(C_{\text {dry }}\right)$ thermal conductance $\left(\mathrm{J} \mathrm{g}^{-1} \mathrm{~h}^{-1}{ }^{\circ} \mathrm{C}^{-1}\right)$ were calculated as $\mathrm{MR} /\left(T_{\mathrm{b}}-T_{\mathrm{a}}\right)$ and $(\mathrm{MHP}-\mathrm{EHL}) /\left(T_{\mathrm{b}}-T_{\mathrm{a}}\right)$, respectively, where MR is metabolic rate, MHP is metabolic heat production, and EHL is evaporative heat loss, and where EWL was converted to EHL using $2.4 \mathrm{~J} \mathrm{mg}^{-1} \mathrm{H}_{2} \mathrm{O}$ (Withers 1992) and MR was converted to MHP using the oxycalorific coefficient at the measured RER for that experiment (interpolated from table 4.2 in Withers 1992; e.g., $19.5 \mathrm{~J} \mathrm{~mL}^{-1} \mathrm{O}_{2}$ at $\mathrm{RER}=0.7$ to $21.4 \mathrm{~J} \mathrm{~mL}^{-1}$ $\mathrm{O}_{2}$ at $\left.\mathrm{RER}=1.0\right)$. Metabolic water production $\left(\mathrm{MWP} ; \mathrm{mL} \mathrm{g}^{-1}\right.$ $\mathrm{h}^{-1}$ ) was also calculated using the measured RER for that experiment after Withers (1992). Relative water economy (RWE) was calculated as MWP/EWL. The $\mathrm{CO}_{2}$ analyzer of one Foxbox (system 2) was not functional; therefore, for nine (of 32) experiments, the $\dot{\mathrm{V}}_{2}$ and EWL were calculated after Koteja (1996), assuming an RER of 0.85. An RER of 0.85 was also assumed when converting MR to joules and calculating MWP for these nine experiments.

Ventilatory measurements were made at the end of each 
experiment, after which the mouse opossum was immediately removed from the chamber, and its $T_{\mathrm{b}}$ was measured using a plastic-tipped thermocouple (connected to a Radio Spares 611234 thermocouple meter) inserted $\sim 1 \mathrm{~cm}$ into the cloaca. Ventilatory variables (respiratory frequency, $f_{\mathrm{R}}$; tidal volume, $V_{\mathrm{T}}$; minute volume, $\mathrm{V}_{\mathrm{I}}$, and oxygen extraction, $E \mathrm{O}_{2}$ ) were calculated after Malan (1973) and Cooper and Withers (2004b). We used the technique of Szewczak and Powell (2003) to mathematically convert our open plethysmograph system to a closed system to account for variation in the time course of calibration injections and breathing pressure pulses. A custom-written Visual Basic data analysis program (P. Withers and C. Cooper) was used for ventilatory calculations. Values of $\mathrm{EO}_{2}$ were calculated using the $\dot{\mathrm{V}}_{2}$ at the time of ventilatory measurements. Values of $T_{\mathrm{b}}$ were obtained for some torpid animals (for which it was certain that they had attained a steady and minimal torpor $\dot{\mathrm{V}}_{2}$ and EWL; $n=4$ of 6 at $T_{\mathrm{a}}=11.5^{\circ} \mathrm{C}$, and $n=3$ of 5 at $T_{\mathrm{a}}=20^{\circ} \mathrm{C}$ ) by removing the animals from the chamber, measuring their $T_{b}$, and then returning them to the chamber to allow them to arouse.

All values are presented as mean \pm SE, where $n=$ number of individuals. Ventilatory values are presented at body temperature and pressure saturated conditions, although standard temperature and pressure dry conditions were used to calculate $E_{2}$. Effects of $T_{\mathrm{a}}$ and torpor on physiological variables were examined with ANOVA with linear a priori contrasts and Student-Newman-Keuls (SNK) post hoc tests. Statistical analyses were conducted using SPSS (student ver. 11.0) and statistiXL (ver. 1.6). The experimental procedures were approved by the UNESP ethics committee (056/06CEA).

\section{Results}

Body mass for the seven male gracile mouse opossums was 29.1 $\mathrm{g}$ (range 12-43.6 g) and for the two females was $19.6 \mathrm{~g}$ (range 12-26 g). Mean $T_{\mathrm{b}}$ of normothermic mouse opossums ranged from $30.6^{\circ} \pm 1.50^{\circ} \mathrm{C}$ at $T_{\mathrm{a}}=12.1^{\circ} \mathrm{C}(n=8)$ to $34.4^{\circ} \pm$ $0.44^{\circ} \mathrm{C}$ at $T_{\mathrm{a}}=32.1^{\circ} \mathrm{C}(n=9$; Fig. $1 \mathrm{~A})$. There was a significant effect of $T_{\mathrm{a}}$ on $T_{\mathrm{b}}$ (linear contrast $P=0.001$ ), with $T_{\mathrm{b}}$ at $11.5^{\circ} \mathrm{C}$ significantly different from that at $32.1^{\circ} \mathrm{C}($ SNK $P=0.021)$. Gracile mouse opossums entered torpor at $12^{\circ}(n=6)$ and $20^{\circ} \mathrm{C}(n=5)$, with $T_{\mathrm{b}}$ significantly lower than for normothermic opossums at these values of $T_{a}\left(F_{1,17}=49.6, P<0.001\right)$. The lowest $T_{\mathrm{b}}$ we measured was $14.6^{\circ} \mathrm{C}$ at $T_{\mathrm{a}}=12^{\circ} \mathrm{C}$. Two mouse opossums with $T_{\mathrm{b}}<20^{\circ} \mathrm{C}$ did not spontaneously arouse from torpor, even after disturbance, although they did return to a normothermic $T_{\mathrm{b}}$ when allowed to rewarm at room temperature. Mouse opossums did, however, always spontaneously arouse at $T_{\mathrm{b}}>20^{\circ} \mathrm{C}$.

There was a significant effect of $T_{\mathrm{a}}$ on $\dot{\mathrm{V}}_{2}$ (linear contrast $P<0.001$; Fig. $1 B$ ) for normothermic gracile mouse opossums, with $\mathrm{MR}$ at $12^{\circ} \mathrm{C}\left(2.28 \pm 0.214 \mathrm{~mL} \mathrm{O}_{2} \mathrm{~g}^{-1} \mathrm{~h}^{-1}\right)$ being higher $(\mathrm{SNK} P<0.001)$ than that at $20^{\circ} \mathrm{C}\left(2.17 \pm 0.108 \mathrm{~mL} \mathrm{O}_{2} \mathrm{~g}^{-1}\right.$ $\mathrm{h}^{-1}$ ). Values of $\mathrm{MR}$ at $12^{\circ}$ and $20^{\circ} \mathrm{C}$ were also higher (SNK $P<0.001)$ than at $T_{\mathrm{a}}$ 's of $28^{\circ}\left(1.12 \pm 0.098 \mathrm{~mL} \mathrm{O}_{2} \mathrm{~g}^{-1} \mathrm{~h}^{-1}\right)$,

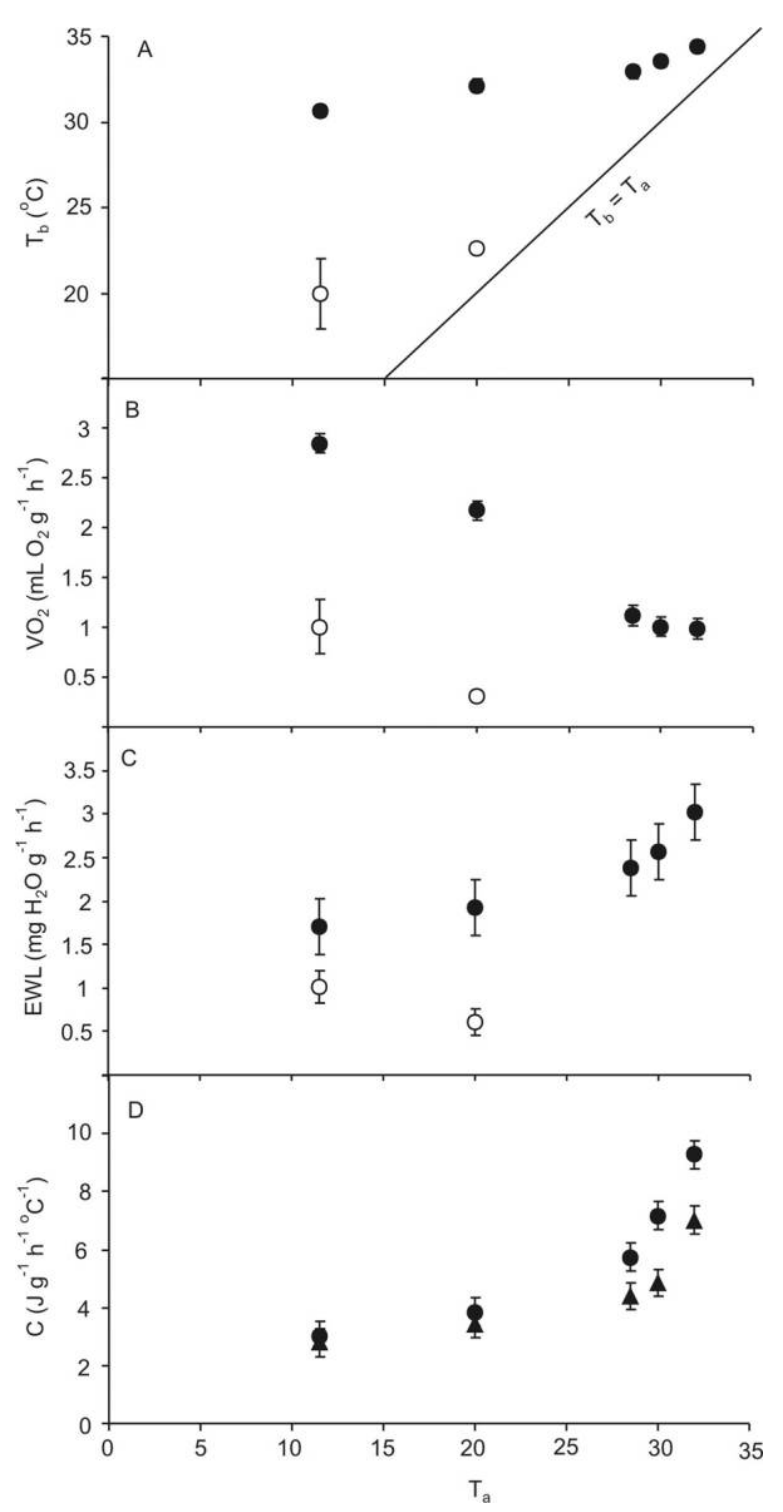

Figure 1 . Body temperature $(A)$, metabolic rate $(B)$, evaporative water loss $(C)$, and wet (circles) and dry (triangles) thermal conductance $(D)$ of gracile mouse opossums at various ambient temperatures. Values are mean \pm SE. For normothermic animals (solid symbols), $n=6$ at each $T_{a}$, except $20^{\circ} \mathrm{C}$, where $n=8$. For torpid animals (open symbols), $n=6$ at $T_{\mathrm{a}}=11.5^{\circ} \mathrm{C}$, and $n=5$ at $T_{\mathrm{a}}=20^{\circ} \mathrm{C}$.

$30^{\circ}\left(1.00 \pm 0.051 \mathrm{~mL} \mathrm{O}_{2} \mathrm{~g}^{-1} \mathrm{~h}^{-1}\right)$, and $32^{\circ} \mathrm{C}(0.98 \pm 0.068 \mathrm{~mL}$ $\left.\mathrm{O}_{2} \mathrm{~g}^{-1} \mathrm{~h}^{-1}\right)$. We consider the mean $\dot{\mathrm{V}}_{2}$ at $30^{\circ} \mathrm{C}$ of $1.00 \pm$ $0.051 \mathrm{~mL} \mathrm{O}_{2} \mathrm{~g}^{-1} \mathrm{~h}^{-1}$ to be basal MR (BMR; mean mass = $31.4 \pm 2.64 \mathrm{~g}$; range $=26.1-43.6 \mathrm{~g}$; all adult individuals $)$. Data for $\dot{\mathrm{V}}_{\mathrm{CO}_{2}}$ essentially mirrored those for $\dot{\mathrm{V}}_{2}$ and are not presented separately here. RER was not influenced by $T_{\mathrm{a}}$ (linear contrast $P=0.181$ ), with the mean RER for all animals over all experiments being $0.87 \pm 0.081$. During torpor, $\dot{\mathrm{V}}_{2}$ was significantly lower $\left(F_{1,21}=103, P<0.001\right.$; Fig. $\left.1 B\right)$ than in normothermic opossums, being $1.00 \pm 0.272$ and $0.30 \pm 0.035 \mathrm{~mL}$ $\mathrm{O}_{2} \mathrm{~g}^{-1} \mathrm{~h}^{-1}$ at $T_{\mathrm{a}}=12^{\circ}$ and $20^{\circ} \mathrm{C}$, respectively, or $35 \%$ and $14 \%$ of the respective normothermic $\dot{\mathrm{V}}_{\mathrm{O}_{2}}$ values. 


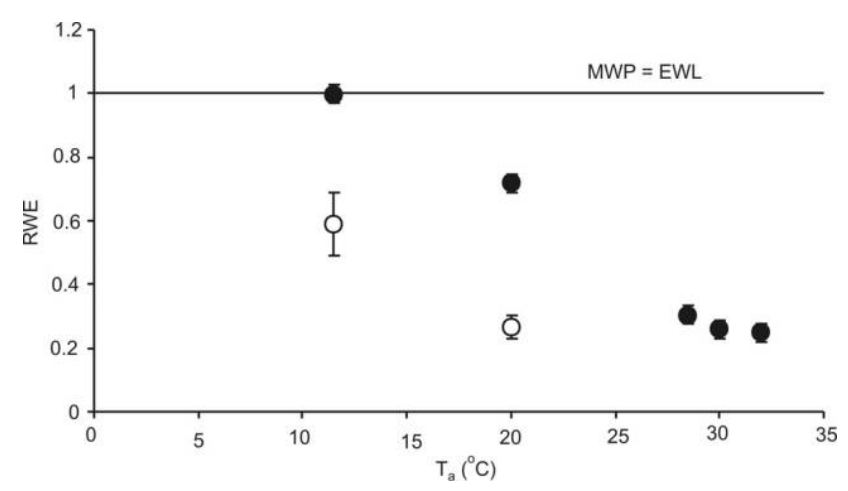

Figure 2. Relative water economy (RWE) of gracile mouse opossums calculated as metabolic water production (MWP)/evaporative water loss (EWL) at various ambient temperatures $\left(T_{\mathrm{a}}^{\prime}\right.$ 's). Values are mean \pm SE. For normothermic animals (solid symbols), $n=6$ at each $T_{\text {a }}$, except $20^{\circ} \mathrm{C}$, where $n=8$. For torpid animals (open symbols), $n=6$ at $T_{\mathrm{a}}=11.5^{\circ} \mathrm{C}$, and $n=5$ at $T_{\mathrm{a}}=20^{\circ} \mathrm{C}$.

There was a significant influence of $T_{\mathrm{a}}$ on both $C_{\text {wet }}$ and $C_{\text {dry }}$ for gracile mouse opossums (Fig. 1D). Both measures of conductance increased with $T_{\mathrm{a}}$ from $3.00 \pm 0.178\left(C_{\text {wet }}\right)$ and $2.78 \pm 0.161 \mathrm{~J} \mathrm{~g}^{-1} \mathrm{~h}^{-1}{ }^{\circ} \mathrm{C}^{-1}\left(C_{\text {dry }}\right)$ at $12^{\circ} \mathrm{C}$ to $9.86 \pm 1.492\left(C_{\text {wet }}\right)$ and $6.17 \pm 0.934 \mathrm{~J} \mathrm{~g}^{-1} \mathrm{~h}^{-1}{ }^{\circ} \mathrm{C}^{-1}\left(C_{\text {dry }}\right)$ at $32^{\circ} \mathrm{C}$ (linear contrast $P<0.001$ for both $C_{\text {wet }}$ and $C_{\text {dry }}$ ). We found that $C_{\text {wet }}$ was significantly higher than $C_{\text {dry }}\left(F_{1,54}=12.2, P=0.001\right)$, and this difference increased as $T_{\mathrm{a}}$ (and thus $\mathrm{EWL}$ ) increased.

EWL increased with $T_{\mathrm{a}}$ from $12^{\circ}$ to $32^{\circ} \mathrm{C}$ (linear contrast $P<0.001$; Fig. $1 C)$. EWL at $T_{\mathrm{a}}=12^{\circ} \mathrm{C}\left(1.70 \pm 0.083 \mathrm{mg} \mathrm{H}_{2} \mathrm{O}\right.$ $\left.\mathrm{g}^{-1} \mathrm{~h}^{-1}\right)$ was lower than values at $T_{\mathrm{a}}=30^{\circ}(2.56 \pm 0.218 \mathrm{mg}$ $\mathrm{H}_{2} \mathrm{O} \mathrm{g}^{-1} \mathrm{~h}^{-1}$; SNK $\left.P=0.030\right)$ and $32^{\circ} \mathrm{C}\left(3.03 \pm 0.190 \mathrm{mg} \mathrm{H}_{2} \mathrm{O}\right.$ $\mathrm{g}^{-1} \mathrm{~h}^{-1}$; SNK $\left.P=0.001\right)$. EWL at $T_{\mathrm{a}}=20^{\circ} \mathrm{C}(1.93 \pm 0.142 \mathrm{mg}$ $\mathrm{H}_{2} \mathrm{O} \mathrm{g}^{-1} \mathrm{~h}^{-1}$ ) was lower than that at $32^{\circ} \mathrm{C}($ SNK $P=0.002)$. There was a significant effect of $T_{\mathrm{a}}$ on EQ, with EQ increasing with $T_{\mathrm{a}}$ (linear contrast $P<0.001$ ) from 0.61 to $3.13 \mathrm{mg} \mathrm{H}_{2} \mathrm{O}$ $\mathrm{mL}^{-1} \mathrm{O}_{2}$ at $11^{\circ}$ and $32^{\circ} \mathrm{C}$, respectively. EQ at $T_{\mathrm{a}}=12^{\circ}$ and $20^{\circ} \mathrm{C}$ was significantly lower $($ SNK $P<0.001)$ than at $T_{\mathrm{a}}=28^{\circ}, 30^{\circ}$, and $32^{\circ} \mathrm{C}$. EQ at $T_{a}=28^{\circ} \mathrm{C}$ was lower than at $T_{\mathrm{a}}=32^{\circ} \mathrm{C}(\mathrm{SNK}$ $P=0.009)$. During torpor, EWL was significantly lower than for normothermic mouse opossums $\left(F_{1,19}=39.7, P<0.001\right)$, being $68 \%\left(1.15 \pm 0.202 \mathrm{mg} \mathrm{H}_{2} \mathrm{O} \mathrm{g}^{-1} \mathrm{~h}^{-1}\right)$ and $31 \%(1.70 \pm$ $0.083 \mathrm{mg} \mathrm{H}_{2} \mathrm{O} \mathrm{g}^{-1} \mathrm{~h}^{-1}$ ) of respective normothermic EWL, at $T_{\mathrm{a}}=12^{\circ}$ and $20^{\circ} \mathrm{C}$, respectively.

MWP decreased with $T_{\mathrm{a}}$ from $12^{\circ}$ to $32^{\circ} \mathrm{C}$ (linear contrast $P<0.001$ ), mirroring the effects of $T_{\mathrm{a}}$ on $\dot{\mathrm{V}}_{\mathrm{O}_{2}}$. RWE was strongly influenced by $T_{\mathrm{a}}$ (linear contrast $P<0.001$; Fig. 2), increasing as $T_{\mathrm{a}}$ decreased, from $0.20 \pm 0.034$ at $T_{\mathrm{a}}=32^{\circ} \mathrm{C}$ to $1.06 \pm$ 0.085 at $T_{\mathrm{a}}=12^{\circ} \mathrm{C}$. RWE at $T_{\mathrm{a}}=12^{\circ} \mathrm{C}$ was significantly higher than that at all other $T_{\mathrm{a}}$ 's (SNK $P<0.001$ ), and RWE at $T_{a}=20^{\circ} \mathrm{C}(0.74 \pm 0.152)$ was higher than at $28^{\circ}, 30^{\circ}$, and $32^{\circ} \mathrm{C}$ $(P<0.001)$. RWE of torpid mouse opossums $(0.26 \pm 0.035$ at $T_{\mathrm{a}}=20^{\circ} \mathrm{C}$ and $0.65 \pm 0.143$ at $T_{\mathrm{a}}=12^{\circ} \mathrm{C}$ ) was lower than that of normothermic mouse opossums at equivalent $T_{\mathrm{a}}\left(F_{1,19}=\right.$ 31, $P<0.001)$.

There was a significant negative relationship between $\mathrm{T}_{\mathrm{a}}$ and $f_{\mathrm{R}}$ for normothermic mouse opossums (linear contrast $P<$
0.001; Fig. $3 A$ ), with $f_{\mathrm{R}}$ ranging from $57 \pm 11.6$ breaths $\min ^{-1}$ at $T_{\mathrm{a}}=32^{\circ} \mathrm{C}$ to $155 \pm 11.6$ breaths $\min ^{-1}$ at $T_{\mathrm{a}}=12^{\circ} \mathrm{C}$. At $T_{\mathrm{a}}=12^{\circ} \mathrm{C}, f_{\mathrm{R}}$ was significantly higher than at all other $T_{\mathrm{a}}$ 's $\mathrm{s}$ (SNK $P<0.001)$, while $f_{\mathrm{R}}$ at $T_{\mathrm{a}}=20^{\circ} \mathrm{C}\left(101 \pm 11.2\right.$ breaths $\left.\mathrm{min}^{-1}\right)$ was higher than that at $T_{\mathrm{a}}=30.3^{\circ}\left(59 \pm 10.8\right.$ breaths $\left.\mathrm{min}^{-1}\right)$ and $32.1^{\circ} \mathrm{C}$. There was no effect of $T_{\mathrm{a}}$ on $V_{\mathrm{T}}$ (linear contrast $P=0.818$; Fig. $3 B$ ), with the mean $V_{\mathrm{T}}$ of all animals at all temperatures being $0.59 \pm 0.042 \mathrm{~mL}$. However, $T_{\mathrm{a}}$ did have a significant effect on $V_{\mathrm{I}}$ (linear contrast $P<0.001$; Fig. $3 C$ ), with $V_{\mathrm{I}}$ at $T_{\mathrm{a}}=12^{\circ}\left(83 \pm 12.8 \mathrm{~mL} \mathrm{~min}^{-1}\right)$ and $20^{\circ} \mathrm{C}\left(79 \mathrm{~mL} \mathrm{~min}^{-1}\right)$ significantly higher than at $28^{\circ}\left(33 \pm 12.8 \mathrm{~mL} \mathrm{~min}{ }^{-1}\right), 30^{\circ}$ $\left(38 \pm 9.4 \mathrm{~mL} \mathrm{~min}^{-1}\right)$, and $32^{\circ} \mathrm{C}\left(34 \pm 8.6 \mathrm{~mL} \mathrm{~min}^{-1}\right)$. There was no effect of $T_{\mathrm{a}}$ on $E \mathrm{O}_{2}$ (linear contrast $P=0.966$; Fig. $3 D$ ), with the mean for all animals and temperatures being $12.4 \% \pm 0.94 \%$. Ventilation could not be measured reliably for torpid gracile mouse opossums because of their infrequent breaths with very small pressure changes, reflecting their small $T_{\mathrm{b}}-T_{\mathrm{a}}$ difference.

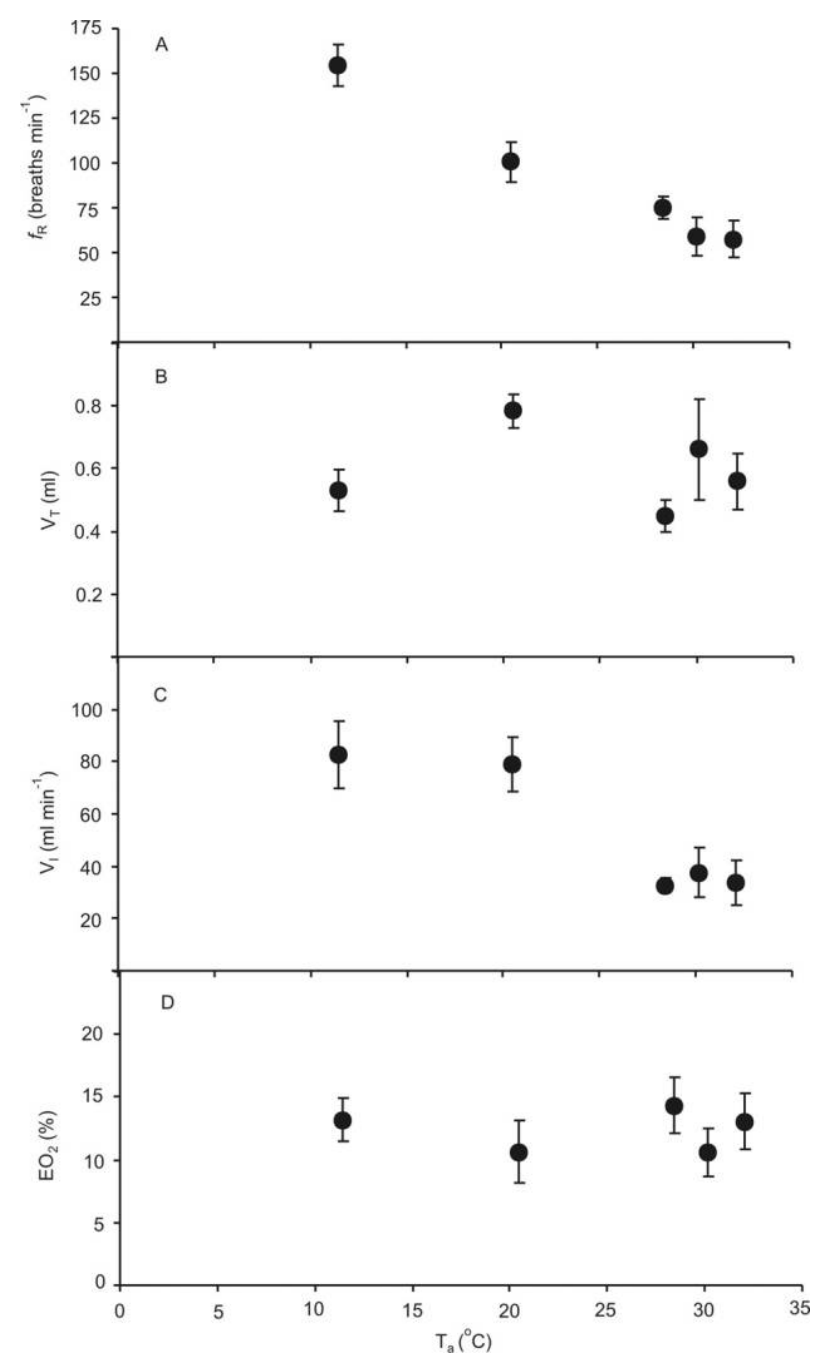

Figure 3. Ventilatory frequency $(A)$, tidal volume $(B)$, minute volume $(C)$, and oxygen extraction $(D)$ of gracile mouse opossums at various ambient temperatures. Values are mean \pm SE. For all animals, $n=$ 6 at each $T_{a}$, except $30^{\circ} \mathrm{C}$, where $n=5$. 


\section{Discussion}

The metabolic, hygric, and ventilatory physiology of the gracile mouse opossum is consistent with that of other marsupials. We find no evidence that this Neotropical marsupial species differs physiologically from other marsupials, despite its geographical distribution and sympatric long-term survival with placental mammals. Significant adaptation of physiological variables of marsupials is therefore not essential for survival of marsupials in the Americas.

\section{Thermal and Metabolic Physiology}

The thermoneutral rest phase $T_{\mathrm{b}}\left(T_{\mathrm{a}}=30^{\circ} \mathrm{C}\right)$ of $33.5 \pm$ $0.68^{\circ} \mathrm{C}$ for normothermic gracile mouse opossums is slightly lower than the $T_{\mathrm{b}}$ of approximately $34.9^{\circ} \mathrm{C}$ for the mouse opossum (presumably Gracilinanus microtarsus) measured by Morrison and $\mathrm{McNab}(1962)$ at $30^{\circ} \mathrm{C}$. Our $T_{\mathrm{b}}$ value is $96 \%$ of that predicted for a marsupial of equivalent mass (Withers et al. 2006). This $T_{\mathrm{b}}$ conforms to the general marsupial allometric relationship, both before and after correction for phylogenetic history, falling within the $95 \%$ prediction limits for a further datum (data from and calculations after Voss et al. 2005; Cooper and Withers 2006; Withers et al. 2006). Normothermic mouse opossums are quite thermolabile, with $T_{\mathrm{b}}$ decreasing significantly with decreasing $T_{\mathrm{a}}$. However, they are able to maintain a substantial $T_{\mathrm{b}}-T_{\mathrm{a}}$ differential during normothermia, even at $T_{\mathrm{a}}^{\prime}$ 's as low as $12^{\circ} \mathrm{C}\left(\Delta T=19.3^{\circ} \pm 1.0^{\circ} \mathrm{C}\right)$.

The BMR of adult gracile mouse opossums $\left(1.00 \mathrm{~mL} \mathrm{O}_{2} \mathrm{~g}^{-1}\right.$ $\mathrm{h}^{-1}$ at $T_{\mathrm{a}}=30^{\circ} \mathrm{C}$ ) is $96 \%$ of that predicted for a marsupial of equivalent mass, calculated by least squares regression from $\log _{10}$-transformed data of Withers et al. (2006), using Hayes and Shonkwiler's $(2006,2007)$ correction for an unbiased antilog transformation for prediction from a log-transformed allometric equation. This correction is necessary because the estimated $y$ value from a double log regression is an arithmetic mean of logarithms, which is equivalent to a geometric mean when untransformed to the original scale and thus underestimates the actual predicted $y$ value (Hayes and Shonkwiler 2006). The BMR of mouse opossums conforms to this allometric relationship both before and after phylogenetic correction (calculated after Withers et al. 2006), falling well inside the $95 \%$ prediction limits for a further datum. We find no evidence for an elevated BMR for this South American marsupial compared with other marsupials, despite McNab's (1978) suggestion that Neotropical South American marsupials have an elevated BMR. The BMR of $1.8 \mathrm{~mL} \mathrm{O}_{2} \mathrm{~g}^{-1} \mathrm{~h}^{-1}$ for a 13-g G. microtarsus, as reported by Morrison and $\mathrm{McNab}$ (1962), is appreciably higher than the BMR of 31-g Gracilinanus agilis, even after accounting for the mass difference (a 13-g G. agilis would have a BMR of $1.24 \mathrm{~mL} \mathrm{O}_{2} \mathrm{~g}^{-1} \mathrm{~h}^{-1}$; MR is proportional to mass $\left.{ }^{0.75}\right)$. However, they measured two MRs for their animal in thermoneutrality; $1.8 \mathrm{~mL} \mathrm{O}_{2} \mathrm{~g}^{-1} \mathrm{~h}^{-1}$ was reported as BMR and $1.00 \mathrm{~mL} \mathrm{O}_{2} \mathrm{~g}^{-1} \mathrm{~h}^{-1}$ was suggested as reflecting a state of hypothermia. Our results for $G$. agilis suggest that their value of $1.00 \mathrm{~mL} \mathrm{O}_{2} \mathrm{~g}^{-1} \mathrm{~h}^{-1}$ was $\mathrm{BMR}$, and the higher value of $1.8 \mathrm{~mL} \mathrm{O}_{2} \mathrm{~g}^{-1} \mathrm{~h}^{-1}$ might have been a hypermetabolic state related to activity and elevated $T_{\mathrm{b}}$ during experiments. This interpretation is supported by consideration of $C_{\text {wet }}$ (we can calculate a similar $C_{\text {wet }}$ for animals from both studies, indicating that the higher MR of G. microtarsus is consistent with their similarly elevated $T_{\mathrm{b}}$ ).

Gracile mouse opossums are significantly thermolabile in their response to varying $T_{\mathrm{a}}$. Nevertheless, they have a substantial thermoregulatory response to decreasing $T_{\mathrm{a}}$, although the variation in $T_{\mathrm{b}}$ with $T_{\mathrm{a}}$ reduces their metabolic response below that expected from their $C_{\text {wet }}$, with the slope of the line relating $\mathrm{MR}$ and $T_{\mathrm{a}}$ being only $0.10 \mathrm{~mL} \mathrm{O}_{2} \mathrm{~g}^{-1} \mathrm{~h}^{-1}{ }^{\circ} \mathrm{C}^{-1}$, compared with a calculated thermoneutral $C_{\text {wet }}$ of $0.36 \pm 0.152 \mathrm{~mL}$ $\mathrm{O}_{2} \mathrm{~g}^{-1} \mathrm{~h}^{-1}{ }^{\circ} \mathrm{C}^{-1}$. By attenuating their metabolic response to low $T_{\mathrm{a}}$, mouse opossums reduce their $T_{\mathrm{b}}-T_{\mathrm{a}}$ differential, reducing heat loss and lowering $\mathrm{O}_{2}$ consumption.

Thermoneutral $C_{\text {wet }}$ of the gracile mouse opossum is $111 \%$ of that predicted from the allometric relationship for marsupials, calculated by least squares regression from $\log _{10}$-transformed data of Withers et al. (2006), using Hayes and Shonkwiler's $(2006,2007)$ unbiased antilog transformation. This $C_{\text {wet }}$ conforms to the general marsupial regression, falling within the 95\% prediction limits both before and after phylogenetic correction (analysis after Cooper and Withers 2006; Withers et al. 2006). We find no evidence that gracile mouse opossums have a significantly elevated $C_{\text {wet }}$ compared with other marsupials, despite McNab's (1978) suggestion that Neotropical South American marsupials have a higher $C_{\text {wet }}$ than other marsupials. The $C_{\text {wet }}$ of $0.36 \mathrm{~mL} \mathrm{O}_{2} \mathrm{~g}^{-1} \mathrm{~h}^{-1}{ }^{\circ} \mathrm{C}^{-1}$ measured in this study at $30^{\circ} \mathrm{C}$ is appreciably higher than the $0.25 \mathrm{~mL} \mathrm{O}_{2} \mathrm{~g}^{-1} \mathrm{~h}^{-1}{ }^{\circ} \mathrm{C}^{-1}$ value reported for $G$. microtarsus by Morrison and $\mathrm{McNab}$ (1962; calculated from the slope of $\dot{\mathrm{V}}_{2}$ against $T_{\mathrm{b}}-T_{\mathrm{a}}$ ). This discrepancy presumably results from differences in calculation techniques and physiological state of the animals. Indeed, if we calculate $C_{\text {wet }}$ as $\mathrm{MR} /\left(T_{\mathrm{b}}-T_{\mathrm{a}}\right)$ for Morrison and McNab's mouse opossum at $T_{\mathrm{a}}=30^{\circ} \mathrm{C}$, it is $0.36 \mathrm{~mL} \mathrm{O}_{2} \mathrm{~g}^{-1} \mathrm{~h}^{-1}{ }^{\circ} \mathrm{C}^{-1}$ $(=1.80 /[34.9-30])$, the same as we found for G. agilis. This indicates that the higher MR of G. microtarsus at thermoneutrality is consistent with their similarly elevated $T_{\mathrm{b}}$.

\section{Ventilation}

Variation of ventilatory parameters of gracile mouse opossums from allometrically predicted values (calculated by least squares regression from $\log _{10}$-transformed data) range from $116 \%$ of predicted for $V_{\mathrm{T}}$ to $142 \%$ of predicted for $V_{\mathrm{I}}$ (Nicol and Maskrey 1980; Hallam and Dawson 1993; Chappell and Dawson 1994; Dawson et al. 2000; Larcombe 2002; Cooper and Withers 2004b; Larcombe and Withers 2006; Larcombe et al. 2006), using Hayes and Shonkwiler's $(2006,2007)$ correction. The value of $E \mathrm{O}_{2}$ is $76 \%$ of that predicted for a 30.7 -g marsupial. All ventilatory parameters conform to the allometric relationships for other marsupials both before and after correction for phylogenetic history (analysis after Cooper and Withers 2006; Withers et al. 2006), falling well within the 95\% prediction limits for each relationship. 
Endothermic mammals accommodate their increased demand for $\mathrm{O}_{2}$ at low $T_{\mathrm{a}}$ by increasing their $V_{\mathrm{I}}$, or their $E \mathrm{O}_{2}$, or both. Like most other marsupials, gracile mouse opossums increase $V_{\mathrm{I}}$ rather than $E \mathrm{O}_{2}$ when their $\mathrm{MR}$ is high at low $T_{\mathrm{a}}$. An increase in $V_{\mathrm{I}}$ is accommodated by an increase in $f_{\mathrm{R}}, V_{\mathrm{T}}$, or both. The degree by which $f_{\mathrm{R}}$ and $V_{\mathrm{T}}$ increase to accommodate a greater $V_{\mathrm{I}}$ in marsupials is dependent on body mass, with larger marsupials having a proportionally larger change in $V_{\mathrm{T}}$ and smaller marsupials a proportionally larger change in $f_{\mathrm{R}}$ at low $T_{\mathrm{a}}$ compared to thermoneutral conditions (Cooper and Withers 2004b). The ventilatory response of gracile mouse opossums to low $T_{\mathrm{a}}$ is typical of small marsupials, with a substantial and statistically significant increase in $f_{\mathrm{R}}$ at low $T_{\mathrm{a}}$ and no significant change in $V_{\mathrm{T}}$.

These ventilatory data for a South American marsupial suggest that these animals are similar to Australian marsupials in terms of their ventilatory physiology. Most ventilatory variables in mammals are constrained by the same physical and chemical parameters (e.g., diffusion, convection, thoracic compliance, blood gases), so any differences between taxa are likely to reflect differing metabolic demands rather than intrinsic differences in the functioning of the respiratory system. Therefore, we would expect ventilatory variables of gracile mouse opossums to conform to those of other marsupials, since their metabolic physiology also conforms to that of other marsupial species.

\section{Evaporative Water Loss}

The EWL of $2.56 \pm 0.218 \mathrm{mg} \mathrm{H}_{2} \mathrm{O} \mathrm{g}^{-1} \mathrm{~h}^{-1}$ for the gracile mouse opossum at the lower limit of thermoneutrality $\left(T_{\mathrm{a}}=\right.$ $30^{\circ} \mathrm{C}$ ) is $79 \%$ of that predicted from the allometric equation for marsupials, calculated by least squares regression of $\log _{10^{-}}$ transformed data from Withers et al. (2006), using Hayes and Shonkwiler's $(2006,2007)$ correction. This EWL conforms to the general marsupial regression, falling within the $95 \%$ prediction limits both before and after phylogenetic correction (analysis after Cooper and Withers 2006; Withers et al. 2006). Despite the Neotropical distribution of gracile mouse opossums and their diet high in preformed water, we find no indication that they have a high water loss compared with Australian marsupials. If anything, EWL of mouse opossums tends to be low rather than high for marsupials. This is surprising, considering that environmental variables do influence the EWL of marsupials (Withers et al. 2006). The low EWL of gracile mouse opossums may reflect a need to conserve water during the dry season, when free water and food (insects; Martins and Bonato 2004; Martins et al. 2006b, 2006c) are less available. Therefore, this Neotropical marsupial may be under similar selection pressure for water conservation as a generalized Australian marsupial, for at least the dry part of the year, and therefore an intrinsically lower EWL would be an adaptive advantage.

Unfortunately, methodological differences between studies make comparisons of EWL for marsupials (and other endotherms) difficult (Cooper et al. 2005). Varying RH in the metabolic chamber, long- versus short-term experimental durations, gravimetric versus instantaneous measurement techniques, and a relatively small number of species measured render the EWL data set for marsupials more variable than that for other physiological parameters (e.g., BMR; Withers et al. 2006). Therefore, it is difficult to evaluate unequivocally the relative EWL of the gracile mouse opossum with respect to other marsupial species. Our measurement protocol is also likely to measure lower rates of EWL than the protocols of many of the studies contributing to the current marsupial EWL data set. We use a flow-through thin-film capacitance hygrometer to measure near-instantaneous evaporative water loss, with long measurement durations, ensuring that minimal water loss values, equivalent to BMR for energy use (i.e., the minimum 20-min mean), are obtained. Gravimetric methods must result in higher values than our near-instantaneous technique and potentially include increased EWL due to bouts of activity, grooming, and even urination/defecation. Short measurement durations (i.e., $<4 \mathrm{~h}$ ) in studies that contribute to the marsupial EWL data set probably also overestimate EWL of small marsupials, by $\sim 45 \%$ (Cooper and Withers 2009).

\section{Relative Water Economy}

The EQ of opossums at the lower limit of thermoneutrality is very high $\left(2.6 \pm 0.27 \mathrm{mg} \mathrm{H}_{2} \mathrm{O} \mathrm{mL} \mathrm{mL}^{-1} \mathrm{O}_{2}\right)$, indicating poor water economy at these high $T_{\mathrm{a}}$ 's. By comparison, an Australian dasyurid, the stripe-faced dunnart, has a thermoneutral EQ of 1.28 and the North American cactus mouse (Peromyscus eremicus) has an EQ of 1.2. Some mammals have thermoneutral EQs $<1$; laboratory mice and rats have EQs of only 0.85 and 0.94 , and desert rodents may have EQs as low as 0.5-0.59 (Hudson 1962).

The RWE of gracile mouse opossums at low $T_{\mathrm{a}}$ indicates that they may not always have an abundance of water but are adapted to conserve water. The point of relative water economy (PRWE), where MWP balances EWL, occurs at approximately $11.5^{\circ} \mathrm{C}$, and the mouse opossums achieve positive water balance at $T_{\mathrm{a}}<11.5^{\circ} \mathrm{C}$. The $T_{\mathrm{a}}$ at which the PRWE occurs is an index of a species' adaptation to limited water availability and is useful for interspecific comparison (MacMillen and Hinds 1983; MacMillen 1990). Hinds and MacMillen (1986) calculated the PRWE for dasuyrid marsupials to be $-3.3^{\circ} \mathrm{C}$ and that of granivorous heteromyid rodents to be $14.1^{\circ} \mathrm{C}$. Granivorous birds have PRWEs between $-18.3^{\circ}$ and $18^{\circ} \mathrm{C}$, with a predicted PRWE for a 30 -g granivorous bird about $12.5^{\circ} \mathrm{C}$ (MacMillen 1990; MacMillen and Baudinette 1993). Thus, the tropical, insectivorous/omnivorous gracile mouse opossum has a PRWE comparable with that of a granivorous desert species. This is somewhat surprising because we may expect a granivorous desert species to have evolved a more efficient water economy. Interestingly, the desert-dwelling stripe-faced dunnart has a substantially lower basal EWL ( $\left.1.81 \mathrm{mg} \mathrm{H}_{2} \mathrm{O} \mathrm{g}^{-1} \mathrm{~h}^{-1}\right)$ and EQ than the gracile mouse opossum but does not attain a positive water economy at $T_{\mathrm{a}}>11^{\circ} \mathrm{C}$ (Cooper et al. 2005).

For normothermic endotherms, the potential to attain a positive water economy at low $T_{\mathrm{a}}$ appears to depend mainly on the pattern of change in EWL with decreasing $T_{\mathrm{a}}$. For gracile mouse opossums, EWL decreased with decreasing $T_{\mathrm{a}}$. Thus an 
increase in MWP (resulting from increased heat production) at low $T_{\mathrm{a}}$ could balance, and then exceed, EWL. The low EQ for mouse opossums at low $T_{\mathrm{a}}$ compared with the higher EQ at higher $T_{\mathrm{a}}$ (Fig. 2) clearly demonstrates this difference. However, EWL remains constant below the lower critical temperature for many dasyurid marsupials (Hinds and MacMillen 1986) and numbats (Cooper and Withers 2002) and even increases for stripe-faced dunnarts (Cooper et al. 2005) and bandicoots (Larcombe and Withers 2006; Larcombe et al. 2006).

Variation in EWL below the thermoneutral zone presumably results from respiratory water loss increasing as a result of increased ventilation (required to accommodate a higher MR at low $T_{\mathrm{a}}$ ). In some species, this increased ventilatory water loss balances or even exceeds the reduction in cutaneous water loss at lower $T_{a}$, resulting in a counterintuitive increase in (or constancy of) total EWL. Presumably, differences in the relationship of $V_{\mathrm{I}}$ and $T_{\mathrm{a}}$ between species and the efficiency of countercurrent heat and water exchange by the respiratory system determine the pattern of EWL below thermoneutrality and, therefore, the potential for a species to achieve positive water economy.

Gracile mouse opossums experience high humidity during periods of higher $T_{\mathrm{a}}$ in the wet season (Martins et al. 2006b, $2006 d$ ), which will reduce EWL in their subtropical environment. They may have a greater need to achieve a more favorable EQ during the cooler but less humid dry season, requiring a large $T_{\mathrm{a}}$ effect on RWE. Unfortunately, the current paucity of detailed and comparable data on EWL, respiration, and RWE makes it difficult to elucidate ecological correlates and infer the adaptive significance of water economy for marsupials. This is an area that merits further investigation.

\section{Torpor}

During torpor in G. microtarsus, $T_{\mathrm{b}}$ drops to as low as $14.6^{\circ} \mathrm{C}$, and spontaneous arousal is observed when $T_{\mathrm{b}}>20^{\circ} \mathrm{C}$ (at $T_{\mathrm{a}}=12^{\circ}$ and $20^{\circ} \mathrm{C}$ ), thus confirming the occurrence of true torpor in another South American marsupial species. However, these mouse opossums may lack the thermogenetic capacity to rewarm from low $T_{\mathrm{b}}$ at low $T_{\mathrm{a}}$. Morrison and McNab (1962) measured $T_{\mathrm{b}}$ values of $27.5^{\circ} \mathrm{C}$ and calculated $T_{\mathrm{b}}$ values of approximately $16^{\circ} \mathrm{C}$ for G. microtarsus when torpid. These minimum defended $T_{\mathrm{b}}$ values for mouse opossums are typical of those for Australian dasyurids and most other didelphid marsupials that undergo daily torpor (McNab 1978; Geiser 1994, 2004b), although the Chilean mouse opossum (Thylamys elegans) has a lower minimum defended $T_{\mathrm{b}}$ of $<5^{\circ} \mathrm{C}$ (Bozinovic et al. 2005).

Torpor can substantially reduce energy requirements (e.g., Song and Geiser 1997; Cooper and Withers 2004a; Geiser $2004 a, 2004 b$ ) and is presumably important for mouse opossums to balance their daily energy budget, even in a tropical environment with relatively high primary productivity. A 14\%$35 \%$ reduction in MR at low $T_{\mathrm{a}}$ is similar to that measured for G. microtarsus (Morrison and McNab 1962) and dasyurid marsupials during daily torpor (Geiser 1994, 2004b; Cooper et al.
2005). A greater MR reduction, to about $1 \%$ of normothermic, is observed for the Chilean mouse opossum at a $T_{a}$ of $5^{\circ} \mathrm{C}$, since their minimum defended $T_{\mathrm{b}}$ during torpor is lower (Bozinovic et al. 2005).

During torpor, absolute EWL is reduced to significantly below normothermic values, with gracile mouse opossums conserving 7-17 mg $\mathrm{H}_{2} \mathrm{O} \mathrm{h}^{-1}$ compared with normothermic animals, representing decreases of $31 \%-68 \%$ of normothermic EWL. There are data on EWL during torpor for only one other marsupial, the stripe-faced dunnart (Cooper et al. 2005). This small dasyurid marsupial also achieves significant absolute water savings during torpor (50-55 $\mathrm{mg} \mathrm{H}_{2} \mathrm{O} \mathrm{h}^{-1}$ ). These reductions are greater than those of the mouse opossum, which may reflect a more important role for torpor in water conservation by the stripe-faced dunnart in its arid habitat.

Despite the absolute water savings, torpor does not facilitate relative water savings for either gracile mouse opossums or stripe-faced dunnarts. The RWE of torpid gracile mouse opossums is significantly lower than that of normothermic individuals (Fig. 2), while for stripe-faced dunnarts, torpor did not change their already negative RWE (Cooper et al. 2005). RWE remains the same for normothermic and torpid gerbils (Gerbillus pusillus; Buffenstein 1985) and is less favorable for torpid cactus mice (MacMillen 1965). This unfavorable effect of torpor on RWE presumably results from a smaller reduction in EWL with torpor than the corresponding reduction in MR (and thus MWP). The loss of a thermoregulatory metabolic increment, and the consequent decrease in $T_{b}$ and $M R$ by a $Q_{10}$ effect (Withers 1992; Guppy and Withers 1999; Geiser 2004a), would substantially reduce MR during torpor even at a moderate $T_{a}$ of $20^{\circ} \mathrm{C}$, whereas the lesser reduction in EWL presumably reflects a lesser decrease in either or both of the cutaneous and respiratory components of EWL.

\section{Ecological and Adaptive Significance}

Despite 110-130 million yr of separate evolution (Wroe and Archer 2006), the physiological bauplan of the gracile mouse opossum provides no evidence that this South American marsupial differs from other marsupials. Marsupials are physiologically conservative, and there is little adaptive variation apparent in their physiology (McNab 2005; Withers et al. 2006).

Body mass is by far the greatest determinant of physiological variables such as BMR, $C, T_{\mathrm{b}}$, EWL, and ventilatory parameters (McNab 2005; Withers et al. 2006), and there is less residual variation in the allometric relationships for these variables in marsupials than in placental mammals and birds. McNab (1978) suggested that Neotropical marsupials have a higher BMR and $C$ than Australian marsupials, reflecting climatic and dietary adaptation. However, our standard physiological data set for the Brazilian gracile mouse opossum provides no evidence that this species differs significantly in terms of any of the physiological variables from other marsupials. There are correlates of physiological variables with environmental factors such as climate and food habits for marsupials, but although highly significant, they explain very little of the overall variation 
in physiological traits (Withers et al. 2006). The various significant environmental correlates for marsupials are too subtle to result in a sufficient difference for a single species to be statistically different from other species (with the exception of the honey possum and marsupial mole; Withers et al. 2006). Thus, the general physiology of marsupials is sufficient to allow them to exploit a range of environmental and biological niches with only minimal adaptive change.

Marsupial physiology appears preadapted to a low-energy niche; on average, marsupials have low rates of standard energy metabolism compared with rates of placental mammals (Dawson and Hulbert 1969), and associated with these values of low MR are comparatively low $T_{\mathrm{b}}$, EWL, and $V_{\mathrm{I}}$ (e.g., Dawson and Hulbert 1969; Cooper and Withers 2004b). McNab (1986, 2005) observed that many groups of placental mammals have BMR and $T_{\mathrm{b}}$ as low as, or even lower than, those of marsupials, but there are no hypermetabolic marsupials, presumably a constraint of the phylogenetic history of this group. This apparent absence of hypermetabolic marsupials may explain the poor competitive record of marsupials with placentals. In Australia, the recent (within the last 4,000 yr) human-facilitated introduction of placental mammals (other than rodents and bats) has been implicated in the competitive and predative extinction of many Australian marsupial species (Lee and Cockburn 1985; Strahan 2002; Corbett 2006). However, South American marsupials have persisted despite a much longer association with placental mammals (about 60 million yr; Wroe and Archer 2006), but it has not been necessary for South American marsupials like the gracile mouse opossum to differ physiologically from Australian marsupials to persist in the face of competition/ predation from placentals. This may reflect marsupials' lowenergy insectivorous/omnivorous niche. It is interesting to note that those marsupials that have persisted in the Americas are generalist insectivores/omnivores that presumably are at no physiological disadvantage and may have MRs similar to those of placental species filling the same niche (McNab 1986, 2005).

Comparison of South American and Australian marsupials enables us to better understand the conservative pattern of ecological adaptation within this mammalian group. However, more complete and reliable physiological data, especially EWL and respiratory variables, are needed for South American marsupials in particular, to more comprehensively compare the physiology of Australian and South American marsupials and to elucidate any adaptive environmental factors.

\section{Acknowledgments}

We thank Denis Briani, Luiz Eduardo Alves, and Leonardo Trevelin for help with trapping. S. U. Neto and V. E. Molina provided access to Clube Nautico Araraquara and logistical support. We would also like to thank the two anonymous reviewers for their constructive comments on the manuscript. The Fundação de Amparo a Pesquisa do Estado de São Paulo (FAPESP; proc. 00/09968-8; A.P.C.-N.) and the Australian Research Council (ARC; DP0665044; C.E.C. and P.C.W.) provided financial support. Permits for scientific expeditions were issued by Conselho Nacional de Desenvolvimento Científico e Tecnológico (CNPq; proc. EXC 023/06-C), and authorization for catching animals was issued by Insitituo Brasileiro deo Meio Ambiente e Recursos Naturais Renováveis (IBAMA; 248/2006CGFAU). A.P.C.-N. received an FAPESP scholarship while at the University of Western Australia and Curtin University. This article is contribution CEDD28-2008 of the Centre for Ecosystem Diversity and Dynamics, Curtin University of Technology.

\section{Literature Cited}

Bozinovic F., J.L.P. Muñoz, D.E. Naya, and A.P. Cruz-Neto. 2007. Adjusting energy expenditures to energy supply: food availability regulates torpor use and organ size in the Chilean mouse opossum Thylamys elegans. J Comp Physiol B 177: 393-400.

Bozinovic F., G. Ruiz, A. Cortes, and M. Rosenmann. 2005. Energetics, thermoregulation and torpor in the Chilean mouse opossum Thylamys elegans (Didelphidae). Rev Chil Hist Nat 78:199-206.

Bozinovic F., G. Ruiz, and M. Rosenmann. 2004. Energetics and torpor of a South American "living fossil," the microbiotheriid Dromiciops gliroides. J Comp Physiol B 174:293297.

Buffenstein R. 1985. The effect of starvation, food restriction, and water deprivation on thermoregulation and average daily metabolic rates in Gerbillus pusillus. Physiol Zool 58:320328.

Chappell M.A. and T.J. Dawson. 1994. Ventilatory accommodation of changing oxygen consumption in dasyurid marsupials. Physiol Zool 67:418-437.

Cooper C.E., B.M. McAllan, and F. Geiser. 2005. Effect of torpor on the water economy of an arid-zone marsupial, the stripefaced dunnart (Sminthopsis macroura). J Comp Physiol B 175:323-328.

Cooper C.E. and P.C. Withers. 2002. The metabolic physiology of the numbat (Myrmecobius fasciatus). J Comp Physiol B 172:669-675.

- 2004a. Patterns of body temperature variation and torpor in the numbat, Myrmecobius fasciatus (Marsupialia: Myrmecobiidae). J Therm Biol 29:277-284.

- 2004b. Ventilatory physiology of the numbat (Myrmecobius fasciatus). J Comp Physiol B 174:107-111.

- 2006. Numbats and aardwolves-how low is low? a re-affirmation of the need for statistical rigour in evaluating regression predictions. J Comp Physiol B 176:623-629.

- 2009. Effects of measurement duration on the determination of basal metabolic rate and evaporative water loss of small marsupials: how long is long enough? Physiol Biochem Zool (forthcoming).

Corbett L. 2006. The Australian dingo. Pp. 745-753 in J.R. Merrick, M. Archer, G.M. Hickey, and M.S.Y. Lee, eds. Evolution and Biogeography of Australasian Vertebrates. Australian Scientific, Oatlands. 
Costa L.P., Y.J.R. Leite, and J.L. Patton. 2003. Phylogeography and systematic notes on two species of gracile mouse opossums, genus Gracilinanus (Marsupialia: Didelphidae) from Brazil. Proc Biol Soc Wash 116:275-292.

Dawson T.J. and A.J. Hulbert. 1969. Standard energy metabolism of marsupials. Nature 221:383.

Dawson T.J., A.J. Munn, C.E. Blaney, A. Krockenberger, and S.K. Maloney. 2000. Ventilatory accommodation of oxygen demand and respiratory water loss in kangaroos from mesic and arid environments, the eastern grey kangaroo (Macropus giganteus) and the red kangaroo (Macropus rufus). Physiol Biochem Zool 73:382-388.

Dawson T.J. and J.M. Olson. 1988. Thermogenic capacities of the opossum Monodelphis domestica when warm and cold acclimated: similarities between American and Australian marsupials. Comp Biochem Physiol 89A:85-91.

Eisenberg J.F. and K.H. Redford. 1999. Mammals of the Neotropics: The Central Neotropics. Vol. 3. Ecuador, Bolivia, Peru, Brazil. University of Chicago Press, Chicago.

Emmons L.H. and F. Feer. 1997. Neotropical Rainforest Mammals: A Field Guide. 2nd ed. University of Chicago Press, Chicago.

Gardner A.L. and G.K. Creighton. 1989. A new generic name for Tate's (1933) microtarsus group of South American mouse opossums (Marsupialia: Didelphidae). Proc Biol Soc Wash 102:3-7.

Geiser F. 1994. Hibernation and daily torpor in marsupials: a review. Aust J Zool 42:1-16.

- 2004a. Metabolic rate and body temperature regulation during hibernation and daily torpor. Annu Rev Physiol 66: 239-274.

- 2004b. The role of torpor in the life of Australia arid zone mammals. Aust Mamm 26:125-134.

Guppy M. and P.C. Withers. 1999. Metabolic depression in animals: physiological perspectives and biochemical generalizations. Biol Rev 74:1-40.

Hallam J.F. and T.J. Dawson. 1993. The pattern of respiration with increasing metabolism in a small dasyurid marsupial. Respir Physiol 93:305-314.

Hayes J.P. and J.S. Shonkwiler. 2006. Allometry, antilog transformations, and the perils of prediction on the original scale. Physiol Biochem Zool 79:665-674.

- 2007. Erratum: allometry, antilog transformations, and the perils of prediction on the original scale. Physiol Biochem Zool 80:556.

Hinds D.S. and R.E. MacMillen. 1986. Scaling of evaporative water loss in marsupials. Physiol Zool 59:1-9.

Hudson J.W. 1962. The role of water in the biology of the antelope ground squirrel Citellus leucurus. Univ Calif Publ Zool 64:1-56.

Koteja P. 1996. Measuring energy metabolism with open-flow respirometric systems: which design to choose? Funct Ecol 10:675-677.

Larcombe A.N. 2002. Effects of temperature on metabolism, ventilation, and oxygen extraction in the southern brown bandicoot Isoodon obesulus (Marsupialia: Peramelidae). Physiol Biochem Zool 75:405-411.

Larcombe A.N. and P.C. Withers. 2006. Thermoregulatory, metabolic and ventilatory physiology of the western barred bandicoot (Perameles bougainville bougainville) in summer and winter. Aust J Zool 54:5-21.

Larcombe A.N., P.C. Withers, and S.C. Nicol. 2006. Thermoregulatory, metabolic and ventilatory physiology of the eastern barred bandicoot (Perameles gunnii). Aust J Zool 54:914.

Lasiewski R.C., A.L. Acosta, and M.H. Bernstein. 1966. Evaporative water loss in birds. I. Characteristics of the open flow method determination, and their relation to estimates of thermoregulatory ability. Comp Biochem Physiol 19:445457.

Lee A.K. and A. Cockburn. 1985. Evolutionary Ecology of Marsupials. Cambridge University Press, Cambridge.

Malan A. 1973. Ventilation measured by body plethysmography in hibernating mammals and in poikilotherms. Respir Physiol 17:32-44.

MacMillen R.E. 1965. Aestivation in the cactus mouse Peromyscus eremicus. Comp Biochem Physiol 16:227-248.

. 1990. Water economy of granivorous birds: a predictive model. Condor 92:379-392.

MacMillen R.E. and R.V. Baudinette. 1993. Water economy of granivorous birds: Australian parrots. Funct Ecol 7:704-712.

MacMillen R.E. and D.S. Hinds. 1983. Water regulatory efficiency in heteromyid rodents: a model and its application. Ecology 64:152-164.

Martins E.G. and V. Bonato. 2004. On the diet of Gracilinanus microtarsus (Marsupialia, Didelphidae) in an Atlantic rainforest fragment in southeastern Brazil. Mamm Biol 69:5860.

Martins E.G., V. Bonato, C.Q. da-Silva, and S.F. Reis. $2006 a$. Partial semelparity in the Neotropical didelphid marsupial Gracilinanus microtarsus. J Mammal 87:915-920.

. 2006b. Seasonality in reproduction, age structure and density of the gracile mouse opossum Graclinanus microtarsus (Marsupialia: Didelphidae) in a Brazilian cerrado. J Trop Ecol 22:461-468.

Martins E.G., V. Bonato, H.P. Pinheiro, and S.F. Reis. 2006c. Diet of the gracile mouse opossum (Gracilinanus microtarsus) (Didelphimorphia: Didelphidae) in a Brazilian cerrado: patterns of food consumption and intrapopulation variation. J Zool (Lond) 269:21-28.

- $2006 d$. Variation in the food-niche width of Gracilinanus microtarsus (Didelphimorphia: Didelphidae) in a cerrado remnant in southeastern Brazil. Mamm Biol 71:304308.

McNab B.K. 1986. Food habits, energetics, and the reproduction of marsupials. J Zool (Lond) 208:595-614.

. 1978. The comparative energetics of Neotropical marsupials. J Comp Physiol 125:115-128.

- 2005. Uniformity in the basal metabolic rate of marsupials: its causes and consequences. Rev Chil Hist Nat 78: 183-198. 
Morrison P.R. and B.K. McNab. 1962. Daily torpor in a Brazilian murine opossum (Marmosa). Comp Biochem Physiol 6:57-68.

Nespolo R.F., L.D. Bacigalupe, P. Sabat, and F. Bozinovic. 2002. Interplay among energy metabolism, organ mass and digestive enzyme activity in the mouse-opossum Thylamys elegans: the role of thermal acclimation. J Exp Biol 205:2697-2703.

Nicol S.C. and M. Maskrey. 1980. Thermoregulation, respiration and sleep in the Tasmanian devil, Sarcophilus harrisii (Marsupialia: Dasyuridae). J Comp Physiol B 140:241-248.

Ribeiro M.C.P. and J.E.P.W. Bicudo. 2007. Oxygen consumption and thermoregulatory responses in three species of South American marsupials. Comp Biochem Physiol A 147: 658-664.

Rossi R.V., G.V. Bianconi, and W.A. Pedro. 2006. Ordem Didelphimorphia. Pp. 27-66 in N.R. Reis, A.L. Peracchi, W.A. Pedro, and I.P. Lima, eds. Mamiferos do Brasil. Divisão de Processos Técnicos da Biblioteca Central, Universidade Estadual de Londrina, Londrina.

Song X. and F. Geiser. 1997. Daily torpor and energy expenditure in Sminthopsis macroura: interactions between food and water availability and temperature. Physiol Zool 70:331337.

Strahan R. 2002. The Mammals of Australia. Reed New Holland, Sydney.

Szewczak J.M. and F.L. Powell. 2003. Open-flow plethysmog- raphy with pressure-decay compensation. Respir Physiol Neurobiol 134:57-67.

Tate G.H.H. 1933. A systematic revision of the marsupial genus Marmosa, with a discussion of the adaptive radiation of the murine opossums (Marmosa). Bull Am Mus Nat Hist 66:1250.

Tyndale-Biscoe H. 2005. Life of Marsupials. CSIRO, Collingwood.

Voss R.S., D.P. Lunde, and S.A. Jansa. 2005. On the contents of Gracilinanus Gardner and Creighton 1989, with the description of a previously unrecognized clade of small didelphid marsupials. Am Mus Nov 3482:1-34.

Withers P.C. 1977. Metabolic, respiratory and haematological adjustments of the little pocket mouse to circadian torpor cycles. Respir Physiol 31:295-307.

- 1992. Comparative Animal Physiology. Saunders College, Philadelphia.

- 2000. Design, calibration and calculation for flowthrough respirometry systems. Aust J Zool 49:445-461.

Withers P.C., C.E. Cooper, and A.N. Larcombe. 2006. Environmental correlates of physiological variables in marsupials. Physiol Biochem Zool 79:437-453.

Wroe S. and M. Archer. 2006. Origins and early radiations of marsupials. Pp. 551-574 in J.R. Merrick, M. Archer, G.M. Hickey, and M.S.Y. Lee, eds. Evolution and Biogeography of Australasian Vertebrates. Australian Scientific, Oatlands. 